\title{
Correlation of placental thickness with birth weight in singleton pregnancies
}

\author{
Mini Bedi' ${ }^{1}$, Hitika Sharma1, Parvinder Singh Sandhu ${ }^{2 *}$, Anshula Minhas ${ }^{1}$
}

\author{
${ }^{1}$ Department of Obstetrics and Gynecology, Adesh Institute of Medical Sciences and Research, Bathinda, Punjab, India \\ ${ }^{2}$ Department of Surgical Oncology, Advanced Cancer Institute, Bathinda, Punjab, India
}

Received: 22 August 2021

Accepted: 14 September 2021

\section{*Correspondence:}

Dr. Parvinder Singh Sandhu,

E-mail: docpssandhu@gmail.com

Copyright: (C) the author(s), publisher and licensee Medip Academy. This is an open-access article distributed under the terms of the Creative Commons Attribution Non-Commercial License, which permits unrestricted non-commercial use, distribution, and reproduction in any medium, provided the original work is properly cited.

\begin{abstract}
Background: The placenta provides the physiologic link between a pregnant woman and the fetus. During pregnancy, the normal placenta increases its thickness at a rate of approximately 1 millimeter per week. The thickness is considered normal throughout the $2^{\text {nd }}$ and $3^{\text {rd }}$ trimester if between 2 and $4 \mathrm{~cm}$. There is a need to identify the fetus failing to reach its growth potential because an early detection of intrauterine growth retardation will be beneficial to obstetric and neonatal care.

Methods: After applying inclusion and exclusion criteria, 251 antenatal women from 24-39 weeks gestation were included in the study. After informed written consent, relevant history, examination, abdominal ultrasound was performed noting fetal biometry and placental thickness. The participants were followed until delivery and birth weight noted. Statistical analysis of birth weight $(<$ and $>2500 \mathrm{gm})$ with placental thickness was done.

Results: Mean age of the study was $25.88 \pm 4.34$ years. The mean placental thickness in group A was $3.33 \pm 0.92 \mathrm{~cm}$ and in group B was $3.38 \pm 0.68 \mathrm{~cm}$. Placental thickness showed a positive correlation with fetal weight $(\mathrm{r}=0.013)$, however it was not statistically significant. Uncomplicated pregnancy group had mean placental thickness of $3.40 \pm 0.70 \mathrm{~cm}$. The difference of mean for placental thickness was statistically significant with respect to medical disorders $(\mathrm{p}=0.042)$.

Conclusions: Placental thickness does increase with increasing birth weight of the fetus and hence, subnormal or more than normal placental thickness is helpful in signalling important maternal conditions that may be detrimental to the fetus.
\end{abstract}

Keywords: Birth weight, Placental thickness, Singleton pregnancy

\section{INTRODUCTION}

The placenta is a fetal organ with important metabolic, endocrine and immunologic functions besides being responsible for the nutrition, respiration and excretion for the fetus. It also acts as a barrier and protects the fetus from noxious agents. ${ }^{1}$ Adequate fetal growth and subsequent normal birth weight depends on the efficient delivery of nutrients from the mother to the fetus via normally functioning utero-placental organ. ${ }^{2}$ Hence, any impairment in the development of placenta may have a profound impact on the developing fetus and thus, pregnancy outcome.
Despite careful antenatal surveillance involving scrupulous examination, an issue of considerable concern is that a large number of low birth weight (LBW) infants are not diagnosed until delivery and such low birth weight or small-for-gestational-age (SGA) infants are susceptible to hypoxia, fetal distress, fetal death and long-term handicaps.

Studies have also shown that diminished placental size precedes fetal growth retardation as IUGR is associated with impoverished villous development and fetoplacental angiogenesis. ${ }^{3,4}$ Thus, the subnormal placental thickness 
for the corresponding gestational age should be evaluated further for any underlying disease condition. ${ }^{5}$

Hence, the present study was aimed to analyse the correlation of placental thickness with the birth weight in normal and IUGR singleton pregnancies.

\section{METHODS}

This hospital-based study was carried out in the Department of Obstetrics and Gynaecology and Department of Radiodiagnosis at Adesh Institute of Medical Sciences and Research, Bathinda, after getting approval from Institutional Ethical and Research committee. It was a prospective observational study carried over a period of one and a half years (April 2018November 2019) with patients being followed up till delivery.

\section{Inclusion criteria}

Singleton pregnancy, gestational age 24-39 weeks.

\section{Exclusion criteria}

Multiple gestation, diabetes, established fetal anomalies, anomalous insertion of cord.

\section{Methodology}

251 pregnant women (24-39 weeks of gestation), outpatients and inpatients, were included in the study applying inclusion and exclusion criteria. After informed written consent, history and physical examination, transabdominal sonographic measurements were performed on GE Voluson E8 Expert Ultrasound Machine, using a 3.5 Hertz curvilinear probe obeying PCPNDT rules 1996.

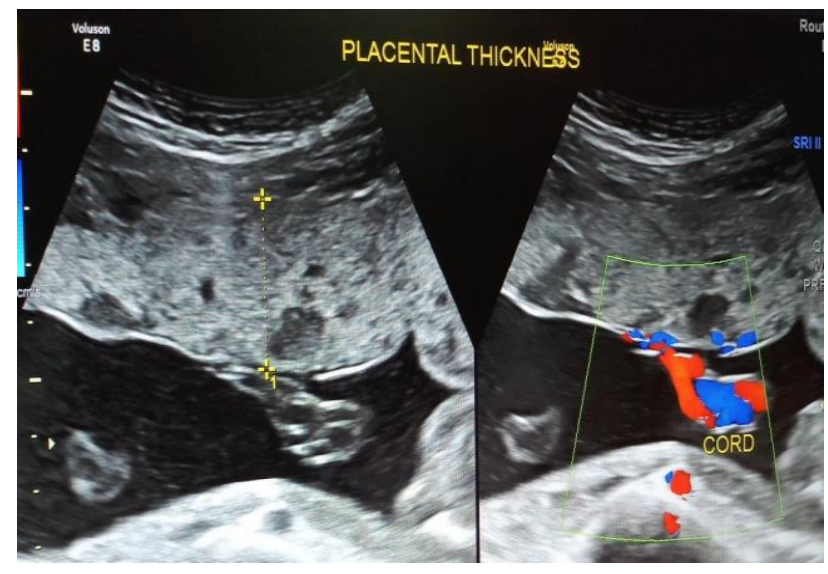

Figure 1: Placental thickness measurement at the level of cord insertion.

The placental thickness was measured at the level of umbilical cord insertion by placing one calliper at the level of cord insertion and other in a perpendicular direction at the level of basal plate of placenta as shown in Figure 1. The retroplacental venous lakes were excluded for the purpose of measurement. Any measurements during uterine contraction were repeated to avoid false localization and measurement.

Subjects were followed until delivery of the baby. Subsequently, placental thickness was correlated with birth weight by categorizing into group A and B of baby weights $<2500$ gm and $\geq 2500$ gm respectively. Statistical analysis was done using SSPS19.0 version.

\section{RESULTS}

There were 251 antenatal women included in the study with an age distribution ranging from 18 years to 44 years with $84.06 \%$ patients belonging to $20-30$ years age group. It was observed that the mean placental thickness in primigravida $(\mathrm{n}=84)$ was $3.51 \mathrm{~cm}$ while in multigravida $(n=167)$ was $3.30 \mathrm{~cm}$, the difference of which was found to be significant ( $\mathrm{p}$ value 0.04 ).

Placental thickness, observed in the study, had a minimum value of $1.40 \mathrm{~cm}$ and a maximum of $6.30 \mathrm{~cm}$, with a mean value of $3.37 \mathrm{~cm}$. Similarly, birth weight ranged from 1290 gm to $5000 \mathrm{gm}$, with a mean value of $2811 \mathrm{gm}$ as tabulated below.

Table 1: Mean age and placental thickness in study.

\begin{tabular}{|lllll|}
\hline Parameter & Min. & Max. & Average & SD \\
\hline Age (years) & 18 & 44 & 25.88 & 4.34 \\
\hline $\begin{array}{l}\text { Placental } \\
\text { thickness (cm) }\end{array}$ & 1.40 & 6.30 & 3.37 & 0.73 \\
\hline $\begin{array}{l}\text { Birth weight } \\
\text { (gm) }\end{array}$ & 1290 & 5000 & 2811 & 421.20 \\
\hline
\end{tabular}

Depending on the localization of placenta in the uterine cavity on ultrasound, it was found that $56.6 \%$ of placenta were anterior, $28.3 \%$ were posteriorly located while $12.7 \%$ were found attached to the fundus. Only $2.4 \%$ subjects in our study had lateral attachment of placenta. The mean placental thickness for anteriorly located placenta was 3.29 $\mathrm{cm}$ while that of fundal, posterior and lateral placenta was $3.40 \mathrm{~cm}, 3.52 \mathrm{~cm}$ and $3.51 \mathrm{~cm}$ respectively.

Of the 251 antenatal women included in the study, a total of 75 women had co morbidities namely- anemia (40), hypothyroidism (18), amniotic fluid disorders (6), Rh negative pregnancy (6), pre-eclampsia (2) and medical disorders (3) (like maternal ASD, asthma, thrombocytopenia) representing $29.9 \%$ whereas the remaining $70.1 \%$ being uncomplicated pregnancies. The mean placental thickness along with their standard deviations among various co morbidities is shown in Table 3. Statistical analysis revealed that difference of mean was significant in the medical disorders group with $\mathrm{p}$ value of 0.04 . 
Table 2: Mean placental thickness in group A and group B.

\begin{tabular}{|c|c|c|c|c|}
\hline \multirow{2}{*}{ Gestational age group } & \multicolumn{2}{|c|}{ Group A birth weight <2500 gm } & \multicolumn{2}{|c|}{ Group B birth weight $\geq 2500$ gm } \\
\hline & $N=49$ & Mean placental thickness & $\mathrm{N}=202$ & Mean placental thickness \\
\hline 24-25 & 0 & - & 10 & $2.75 \pm 0.36$ \\
\hline$>25-26$ & 1 & $2.35 \pm 0.00$ & 9 & $2.75 \pm 0.23$ \\
\hline$>26-27$ & 3 & $2.90 \pm 0.83$ & 7 & $3.09 \pm 0.56$ \\
\hline$>27-28$ & 4 & $3.40 \pm 1.45$ & 11 & $2.94 \pm 0.51$ \\
\hline$>28-29$ & 3 & $2.65 \pm 1.56$ & 12 & $3.20 \pm 0.43$ \\
\hline$>29-30$ & 4 & $3.54 \pm 0.76$ & 8 & $3.25 \pm 0.81$ \\
\hline$>30-31$ & 7 & $3.29 \pm 0.70$ & 5 & $3.38 \pm 0.78$ \\
\hline$>31-32$ & 2 & $3.31 \pm 0.13$ & 13 & $3.33 \pm 0.42$ \\
\hline$>32-33$ & 11 & $3.79 \pm 1.03$ & 23 & $3.46 \pm 0.48$ \\
\hline$>33-34$ & 9 & $3.08 \pm 0.88$ & 26 & $3.30 \pm 0.51$ \\
\hline$>34-35$ & 3 & $3.55 \pm 0.39$ & 31 & $3.67 \pm 0.63$ \\
\hline$>35-36$ & 1 & $3.22 \pm 0.00$ & 29 & $3.77 \pm 0.73$ \\
\hline$>\mathbf{3 6 - 3 7}$ & 0 & - & 9 & $3.24 \pm 0.99$ \\
\hline$>37-38$ & 1 & $3.55 \pm 0.00$ & 8 & $3.62 \pm 0.91$ \\
\hline$>38-39$ & 0 & - & 1 & $5.88 \pm 0.00$ \\
\hline
\end{tabular}

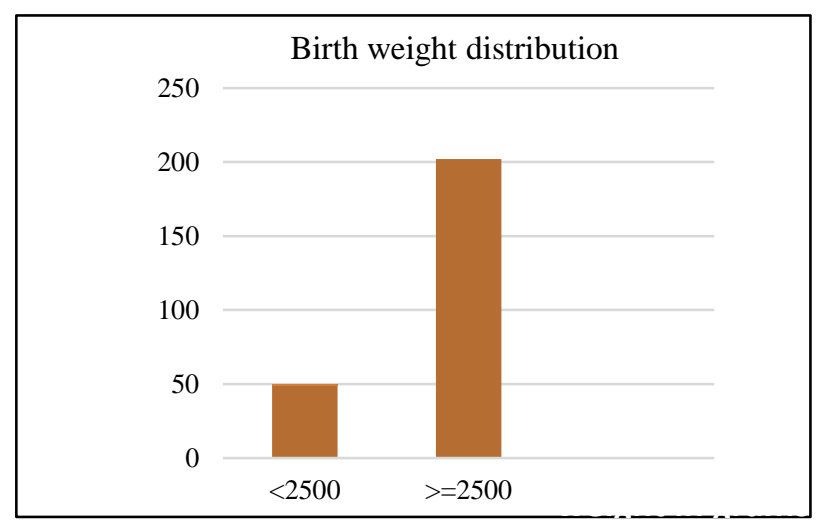

Figure 2: Birth weight distribution in the study.

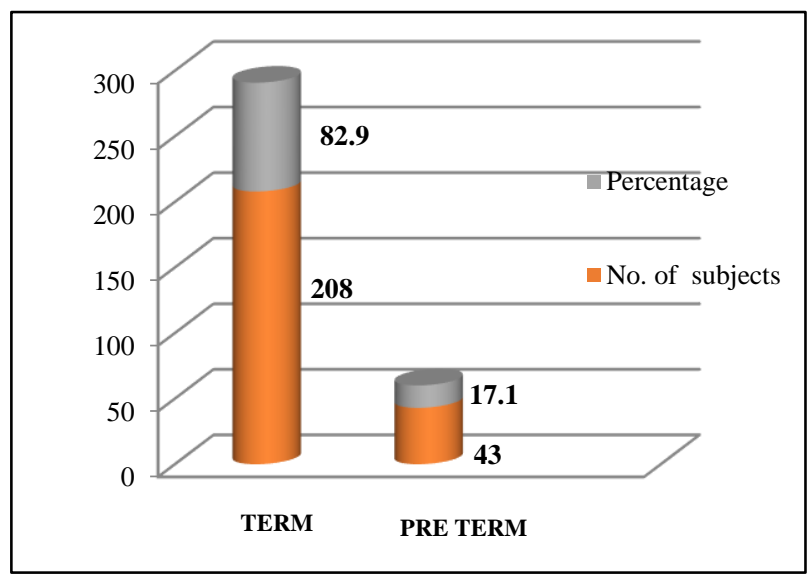

Figure 3: Gestational age at birth.

All 251 patients were followed up till delivery and the birth weight of each child was noted. Out of these, 43 (17.1\%) had pre-term delivery and the remaining 208 subjects had delivery at term (Figure 3 ). There were 49 low birth weight i.e. birth weight $<2500$ gm (group A) babies and the rest (202) weighed $\geq 2500$ gm (group B) as shown in Figure 2.

Table 3: Placental thickness among co morbidities.

\begin{tabular}{|ll|}
\hline Comorbidities (n) & $\begin{array}{l}\text { Mean placental } \\
\text { thickness } \pm \text { SD (in cm) }\end{array}$ \\
\hline Anemia (40) & $3.29 \pm 0.62$ \\
\hline Hypothyroidism (18) & $3.03 \pm 0.62$ \\
\hline Amniotic fluid disorders (6) & $3.98 \pm 1.26$ \\
\hline Rh negative pregnancy (6) & $2.83 \pm 0.98$ \\
\hline Pre-eclampsia (2) & $3.19 \pm 0.76$ \\
\hline Medical disorders (3) & $4.70 \pm 0.47$ \\
\hline Uncomplicated (176) & $3.40 \pm 0.70$ \\
\hline
\end{tabular}

The placental thickness in group A (i.e. birth weight $<2500$ gm) and in group B (i.e. those that weighed $\geq 2500 \mathrm{gm}$ ) were studied. The mean of placental thickness at different gestational age in both the groups is shown in Table 2. On applying correlation coefficient, the study showed a positive correlation of placental thickness with birth weight with $\mathrm{r}=0.013$, however, it was not found to be statistically significant $(\mathrm{p}=0.838)$.

\section{DISCUSSION}

It has been seen that from the $22^{\text {nd }}$ week to the $35^{\text {th }}$ week of gestation, the placental thickness in millimeters coincides almost exactly with the gestational age in weeks. ${ }^{6}$

\section{Small and thin placenta}

Placenta less than $2 \mathrm{~cm}$ thick, have been shown to be present in cases of fetal malformations, chronic uterine infections with CMV, HSV, gestational hypertension, pre conceptional diabetes and in women with low pre- 
pregnancy weight and less weight gain during the pregnancy who have a low blood volume expansion in pregnancy. ${ }^{7,8}$ Small placentae are associated with increased frequency of preeclampsia, small for dates fetus, fetal growth restriction and still births. ${ }^{9,10}$

\section{Large and thick placenta}

According to the literature, a placenta more than $4 \mathrm{~cm}$ thick over its entire extent has an association with maternal diabetes mellitus, fetal hydrops and intrauterine fetal infections. Common causes of unusually large placenta are villous edema, severe maternal anemia, congenital syphilis, large intervillous thrombi and large subchorionic haematoma. Thick placenta is associated with increased rates of placental abruption, NICU admissions and anomalies. ${ }^{11,12}$

In our study, it was found that 42 subjects had placental thickness more than $4 \mathrm{~cm}$. Out of these, 7 subjects delivered babies with birth weight less than $2500 \mathrm{gm}$ and required NICU admissions. One patient with birth weight of the baby $1400 \mathrm{gm}$ was an IVF conception with hypothyroidism and had PPROM. Another patient whose baby weighed $1400 \mathrm{gm}$ had polyhydramnios with PPROM with cord presentation. Similarly, Elchalal et al stated that sonographically thick placenta $\left(>4 \mathrm{~cm}\right.$ or $>90^{\text {th }}$ percentile) is associated with increased perinatal mortality and morbidity like fetal anomalies, small for gestational age (SGA), large for gestational age (LGA) infants at term. ${ }^{11}$ Since our study did not include anomalies, so the same cannot be commented upon, but $16.67 \%$ babies did require NICU admission despite the fact that they had no malformations.

On the other hand, of the total 49 subjects who delivered babies weighing less than $2500 \mathrm{gm}, 7$ subjects (14\% of LBW babies) had placental thickness more than $4 \mathrm{~cm}$ which is similar to the study by Elchalal et al. ${ }^{11}$ There were no LGA babies in the same group in our study.

The present study also analysed the mean placental thickness in two groups divided on the basis of birth weight into group A (birth weight $<2500 \mathrm{gm}$ ) and group B (birth weight $\geq 2500 \mathrm{gm}$ ). The mean placental thickness in group A was $3.33 \pm 0.92 \mathrm{~cm}$ while that in group B was $3.38 \pm 0.68 \mathrm{~cm}$, the difference of which was not found to be statistically significant.

In a similar study done by Mathai et al, the study population- 498 antenatal women, were divided into two groups based on outcome fetal weight. Group A included fetal weight $<2500 \mathrm{gm}$ and group B included fetal weight $>2500 \mathrm{gm}$ as in our study. Placental thickness was calculated from gestational weeks 24 to 39 . The ' $r$ ' value indicating correlation between placental thickness and gestational age for group A was 0.325 and group B was 0.135 ( $p$ value 0.01 ). The placental thickness mean values for Group A was, thus, found to be higher when compared to Group B. ${ }^{13}$
In a study by Wolf et al placental volume and fetal weight were estimated by ultrasound at regular intervals from 1620 weeks in 18 patients. In 7 normal cases, placental and fetal growth followed a sigmoid or nearly linear pattern. In 11 cases with an abnormal outcome of pregnancy (fetal death, fetal distress necessitating caesarean section or neonatal weight below $10^{\text {th }}$ percentile), placental growth retardation always preceded fetal complications or fetal growth retardation by at least three weeks. ${ }^{3}$

Similarly, Habib concluded in his study that placental diameter and thickness measurements are valuable parameters for predicting low birth weight infants. ${ }^{14} \mathrm{He}$ also framed a warning limit of placental thickness of $2 \mathrm{~cm}$ at 36 weeks gestation as a predictor of LBW infants and subsequent IUGR. ${ }^{5}$ However, in our study only one patient had a placental thickness of $<2 \mathrm{~cm}$, i.e. $1.4 \mathrm{~cm}$, but the patient delivered a baby of birth weight $2800 \mathrm{gm}$ (not low birth weight). Also, it is imperative to note that the same patient was an Rh negative pregnancy with epilepsy, so a lesser placental thickness may be in part due to the comorbidities, which though has been observed in the study but establishing its significance needs further evaluation.

Limitations of the study are the fetuses with congenital anomalies were excluded from the study and hence, the study cannot comment on the same. Also, the comorbid conditions need to be studied in detail as a properly matched study in order to establish a cause-effect relationship between various co morbid conditions and the placental thickness.

\section{CONCLUSION}

The maternal milieu serves to affect the placental thickness and in turn the fetus and thus, may land up a fetus in an intensive care unit and increase to the family expenses, adding burden to the health care. Therefore, a subnormal or more than normal placental thickness for the gestational age should signal investigating the case further for maternal conditions like diabetes mellitus, pre-eclampsia, fetal growth restriction, hypothyroidism, hydrops fetalis and intrauterine infections such as CMV and HSV.

Thus, laying down emphasis on the fact that as vital a structure as placenta for the in-utero life needs to be examined carefully and a simple tool of measuring placental thickness is really helpful in signalling important maternal conditions detrimental to the fetus.

Funding: No funding sources Conflict of interest: None declared

Ethical approval: The study was approved by the Institutional Ethics Committee

\section{REFERENCES}

1. Percival R, Holland EL Sir, Brews A. Holland and Brews Manual of Obstetrics. 16th edin. B L Churchill Livingstone Pvt. Ltd; 1998:23. 
2. Azpurua H, Funai EF, Coraluzzi LM, Doherty LF, Sasson IE, Kliman M, et al. Determination of placental weight using two-dimensional sonography and volumetric mathematic modelling. Am J Perinatol. 2010;27(02):151-5.

3. Wolf H, Oosting H, Treffers PE. Second-trimester placental volume measurement by ultrasound: prediction of fetal outcome. Am J Obstet Gynecol. 1989;160(1):121-6.

4. Mayhew TM, Wijesekara J, Baker PN, Ong SS. Morphometric evidence that villous development and fetoplacental angiogenesis are compromised by intrauterine growth restriction but not by preeclampsia. Placenta. 2004;25(10):829-33.

5. Karthikeyan T, Subramaniam RK, Johnson WM, Prabhu K. Placental thickness and its correlation to gestational age and foetal growth parameters- a cross sectional ultrasonographic study. J Clin Diagn Res. 2012;6(10):1732-5

6. Dudley NJ, Fagan DG, Lamb MP. Ultrasonographic placental grade and thickness: associations with early delivery and low birth weight. $\mathrm{Br} \mathrm{J}$ Radiol. 1993;66(782):175-7.

7. Evers IM, Nikkels PG, Sikkema JM, Visser GH. Placental pathology in women with type 1 diabetes and in a control group with normal and large-forgestational-age infants. Placenta. 2003;24(8-9):81925 .

8. Kinare AS, Natekar AS, Chinchwadkar MC, Yajnik $\mathrm{CS}$, Coyaji KJ, Fall $\mathrm{CH}$, et al. Low midpregnancy placental volume in rural Indian women: a cause for low birth weight? Am J Obstet Gynecol. 2000;182(2):443-8.
9. Wolf H, Oosting H, Treffers PE. A longitudinal study of the relationship between placental and fetal growth as measured by ultrasonography. Am J Obstet Gynecol. 1989;161(5):1140-5.

10. Hoogland HJ, de Haan J, Martin Jr CB. Placental size during early pregnancy and fetal outcome: a preliminary report of a sequential ultrasonographic study. Am J Obstet Gynecol. 1980;138(4):441-3.

11. Elchalal U, Ezra Y, Levi Y, Bar-Oz B, Yanai N, Intrator $\mathrm{O}$, et al. Sonographically thick placenta: a marker for increased perinatal risk- a prospective cross-sectional study. Placenta. 2000;21(2-3):268-72.

12. Dombrowski MP, Wolfe HM, Saleh A, Evans MI, O'Brien J. The sonographically thick placenta: a predictor of increased perinatal morbidity and mortality. Ultrasound Obstet Gynecol. 1992;2(4):2525 .

13. Mathai BM, Singla SC, Nittala PP, Chakravarti RJ, Toppo JN. Placental thickness: its correlation with ultrasonographic gestational age in normal and intrauterine growth-retarded pregnancies in the late second and third trimester. J Obstet Gynecol India. 2013;63(4):230-3.

14. Habib FA. Prediction of low birth weight infants from ultrasound measurement of placental diameter and placental thickness. Ann Saudi Med. 2002;22(56):312-4.

Cite this article as: Bedi M, Sharma $\mathrm{H}$, Sandhu PS, Minhas A. Correlation of placental thickness with birth weight in singleton pregnancies. Int J Reprod Contracept Obstet Gynecol 2021;10:3812-6. 